\title{
Modeling and Optimization of Advanced Single- and Multijunction Solar Cells Based on Thin-Film a-Si:H/SiGe Heterostructure
}

\author{
Abdolnabi Kosarian and Peyman Jelodarian \\ Department of Electrical Engineering, Shahid Chamran University of Ahvaz, Ahvaz 61357-831351, Iran \\ Correspondence should be addressed to Peyman Jelodarian, p.jelodarian@yahoo.com
}

Received 4 August 2011; Accepted 13 September 2011

Academic Editors: O. O. Fasina and B. S. Hyun

Copyright ( $) 2011$ A. Kosarian and P. Jelodarian. This is an open access article distributed under the Creative Commons Attribution License, which permits unrestricted use, distribution, and reproduction in any medium, provided the original work is properly cited.

\begin{abstract}
In amorphous thin-film p-i-n solar cell, a thick absorber layer can absorb more light to generate carriers. On the other hand, a thin i-layer cannot absorb enough light. Thickness of the i-layer is a key parameter that can limit the performance of solar cell. Introducing $\mathrm{Ge}$ atoms to the $\mathrm{Si}$ lattice in Si-based solar cells is an effective approach in improving their characteristics. Especially, current density of the cell can be enhanced without deteriorating its open circuit voltage, due to the modulation of material bandgap and the formation of a heterostructure. This work presents a novel numerical evaluation and optimization of an amorphous silicon double-junction structure thin-film solar cell (a-SiGe:H/a-Si:H) and focuses on optimization of a-SiGe:H mid-gap singlejunction solar cell based on the optimization of the Ge content in the film, thickness of i-layer, p-layer and doping concentration of p-layer in a (p-layer a-Si:H/i-layer a-SiGe:H/n-layer a-Si:H) single-junction thin-film solar cell. Optimization shows that for an appropriate Ge concentration, the efficiency of a-Si:H/a-SiGe solar cell is improved by about $6.5 \%$ compared with the traditional a-Si:H solar cells.
\end{abstract}

\section{Introduction}

Hydrogenated amorphous silicon-germanium alloys (aSiGe:H) are widely used in multijunction solar cells because their optical band gap shifts to lower energies with increasing germanium concentration. Besides the enhanced optical absorption for photons with longer wavelengths, the electronic properties, which are relevant for photovoltaic applications, strongly deteriorate by increasing Ge concentration in a$\mathrm{Si}: H$. however, a-SiGe:H layers have been applied successfully as bottom cells in stacked solar cells since 1982. Improvement of solar cell efficiency and reduction of active cell thickness are both very important from economical and technological aspects. In order to avoid a drastic reduction of the shortcircuit current $\left(J_{\mathrm{SC}}\right)$ in a cell with small thickness, it is necessary to increase absorbance of the material and optimize the cell structure [1]. The use of a lower band-gap material such as a-SiGe in the active base region of the cell is a possible approach, given their compatibility with the mature Si-based cell process. An appreciable increase of photocurrent $\left(J_{\mathrm{SC}}\right)$ in the small-band-gap a-SiGe material is highly expected, because of the increased absorption of photons $[2,3]$. On the other hand, a drop in the open-circuit voltage $\left(V_{\mathrm{OC}}\right)$, due to the reduction of the SiGe band-gap with increasing Ge concentration, should be considered and avoided in the optimization of the cell behaviour. As a result, a compromise between the cell parameters is necessary in the optimization procedure. The optimization of band offset between a-SiGe and a-Si either in the valence band $\left(E_{\mathrm{V}}\right)$ or in the conduction band $\left(E_{\mathrm{C}}\right)$ can help to design a more effective back-surface field, where the photo-generated carriers from the highly dislocated surfaces and interfaces are reflected, thus at the backside of the cell the recombination velocity is significantly decreased. The band-offset of $E_{\mathrm{V}}$ and $E_{\mathrm{C}}$ at the SiGe/Si heterointerface is dependent on the Ge concentration in the film. In addition to less surface recombination velocity, the smaller band gap $\left(E_{\mathrm{g}}\right)$ in high Ge concentration SiGe film has a larger light absorption coefficient, which can lead to more electronhole pair generation and higher $J_{\mathrm{SC}}$. Both of them can result in higher cell efficiency of the a-SiGe-based solar cell. 


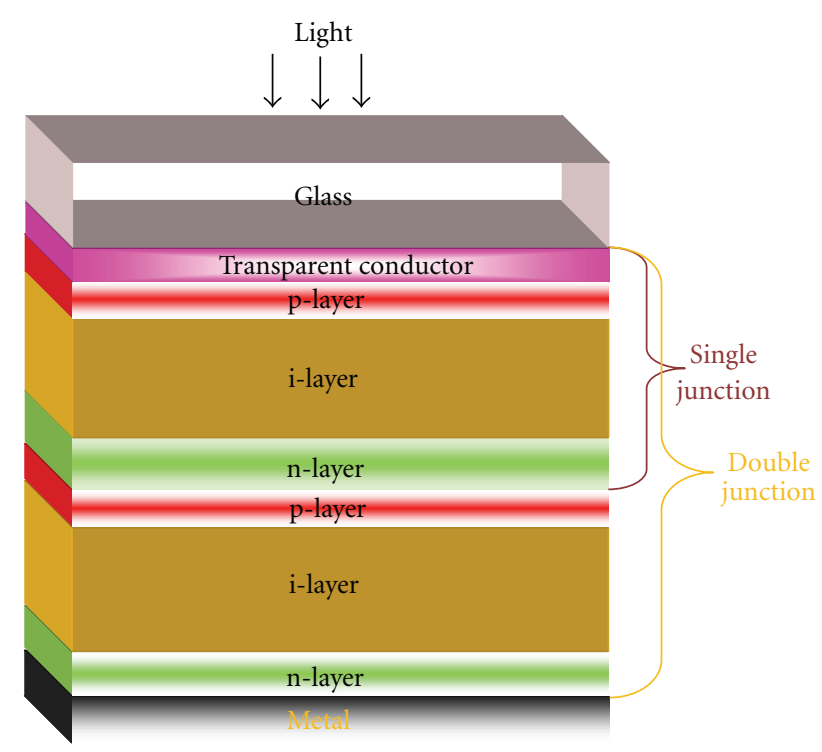

Figure 1: The structure of double-junction a-Si:H solar cell.

An indium tin oxide (ITO) film is used as an antireflection (AR) film.

Maximizing the output power for a given solar spectrum is a primary goal in the multijunction solar cell design. For manufacturing the multijunction solar cells, the individual junction layers are put in series, thereby the overall output current is limited to that of the junction layer producing the lowest current. The solution to optimization of a multijunction design involves both the design of individual junction layers which produce an optimum output power and the design of a series stacked configuration of these junction layers which yields the highest possible overall output current.

To generate free electrons and holes in the absorber layer (i-layer), the top layer is made transparent and as thin as possible so that most of incident light will pass right through it. The $\mathrm{p}$ and $\mathrm{n}$ layers (produced by doping a-Si) will create an electric field across the entire intrinsic region to induce electron movement in that layer. Figure 1 shows a double junction structure for a p-i-n a-Si solar cell used in this work. The a-SiGe substrate with the lowest band gap from 1.4 to $1.6 \mathrm{eV}$ captures the green and red photons of the solar spectrum. However, the a-Si:H, placed on top of the cell, has a band gap of about $1.8 \mathrm{eV}$ and serves to absorb the blue photons.

\section{Numerical Modeling}

Referring to its $I-V$ characteristics, the most important parameters of a solar cell are the short-circuit current $\left(J_{\mathrm{SC}}\right)$, the open-circuit voltage $\left(V_{\mathrm{OC}}\right)$, fill factor $(\mathrm{FF})$, and efficiency $(\eta)$. The short-circuit current is due to the generation and collection of light-generated carriers. So ideally, it is equal to the light-generated current and is the largest current that can flow through the solar cell. However, an appreciable fraction of the generated carriers recombine in the bulk and interface. The recombination losses are characterized by the diffusion length and the minority carrier lifetime in the active region.
The spectral response, the ratio of the collected carriers to the incoming photon flux at a given wavelength in a solar cell, is given by [4]

$$
S R_{\text {in }}(\lambda)=\frac{J_{\mathrm{ph}}(\lambda)}{q \phi(\lambda)(1-R(\lambda))},
$$

where $J_{\mathrm{ph}}(\lambda)$ is the current density at a given wavelength, $q$ is the electron charge, $\phi(\lambda)$ is the monochromatic photoflux, and $R(\lambda)$ is the reflectivity. The fill factor (FF), which is a parameter concerning the maximum power generated by a solar cell, is defined as

$$
\mathrm{FF}=\frac{V_{\mathrm{mp}} \times I_{\mathrm{mp}}}{V_{\mathrm{OC}} \times I_{\mathrm{SC}}}=\frac{P_{\max }}{V_{\mathrm{OC}} \times I_{\mathrm{SC}}},
$$

where $V_{\mathrm{mp}}$ and $I_{\mathrm{mp}}$ are the maximum voltage and maximum current at the maximum power, respectively. The efficiency $\eta$ is defined as the ratio of energy output from the solar cell to the input energy from the sunlight:

$$
\eta=\frac{P_{\max }}{P_{\text {in }}}=\frac{V_{\mathrm{OC}} I_{\mathrm{SC}} \mathrm{FF}}{P_{\text {in }}} .
$$

It is the most important and commonly used parameter to evaluate the performance of a solar cell.

Modelling of device is based on the simultaneous solution of transport equations, such as, Poisson's equations, continuity equations and current density equations for holes and electrons:

$$
\begin{gathered}
-\nabla \cdot \varepsilon \nabla \psi=q \rho, \\
\nabla \cdot J_{p}=q(G-R), \\
\nabla \cdot J_{p}=-q(G-R),
\end{gathered}
$$

where $\varepsilon$ is the dielectric constant, $\psi$ is the homojunction hole potential, $-q$ is the electron charge, $G$ is the generation rate for carriers, and $R$ is the recombination rate. The net charge carrier density $\rho$ is given by the following expression:

$$
\rho=p-n+n_{T}-p_{T}+N_{\text {tail }}+N_{\mathrm{DS}}
$$

where $p$ and $n$ are the free hole and electron densities, $n_{T}$ and $p_{T}$ are the concentrations of ionized acceptor and donors, and $N_{\text {tail }}$ and $N_{\text {DS }}$ are the net charge densities due to the trapping of holes and electrons in tail states and dangling bond states, respectively. The values for $n_{T}$ and $p_{T}$ are calculated from the energy levels and total densities of donors and acceptors and from the spatially varying concentrations of free carriers in the solar cell.

The positive current densities due to transport by holes $J_{p}$ and by electrons $J_{n}$ are given by [5]

$$
\begin{gathered}
J_{p}=-q \mu_{p} p \nabla\left(\psi-V_{p}\right)-k T \mu_{p} \nabla p, \\
J_{n}=-q \mu_{n} n \nabla\left(\psi-V_{n}\right)-k T \mu_{n} \nabla n,
\end{gathered}
$$

where $\mu_{p}$ and $\mu_{n}$ are the hole and electron mobilities, respectively. $V_{p}$ and $V_{n}$ are valence and conduction band parameters to account for heterojunctions and graded band gaps. 

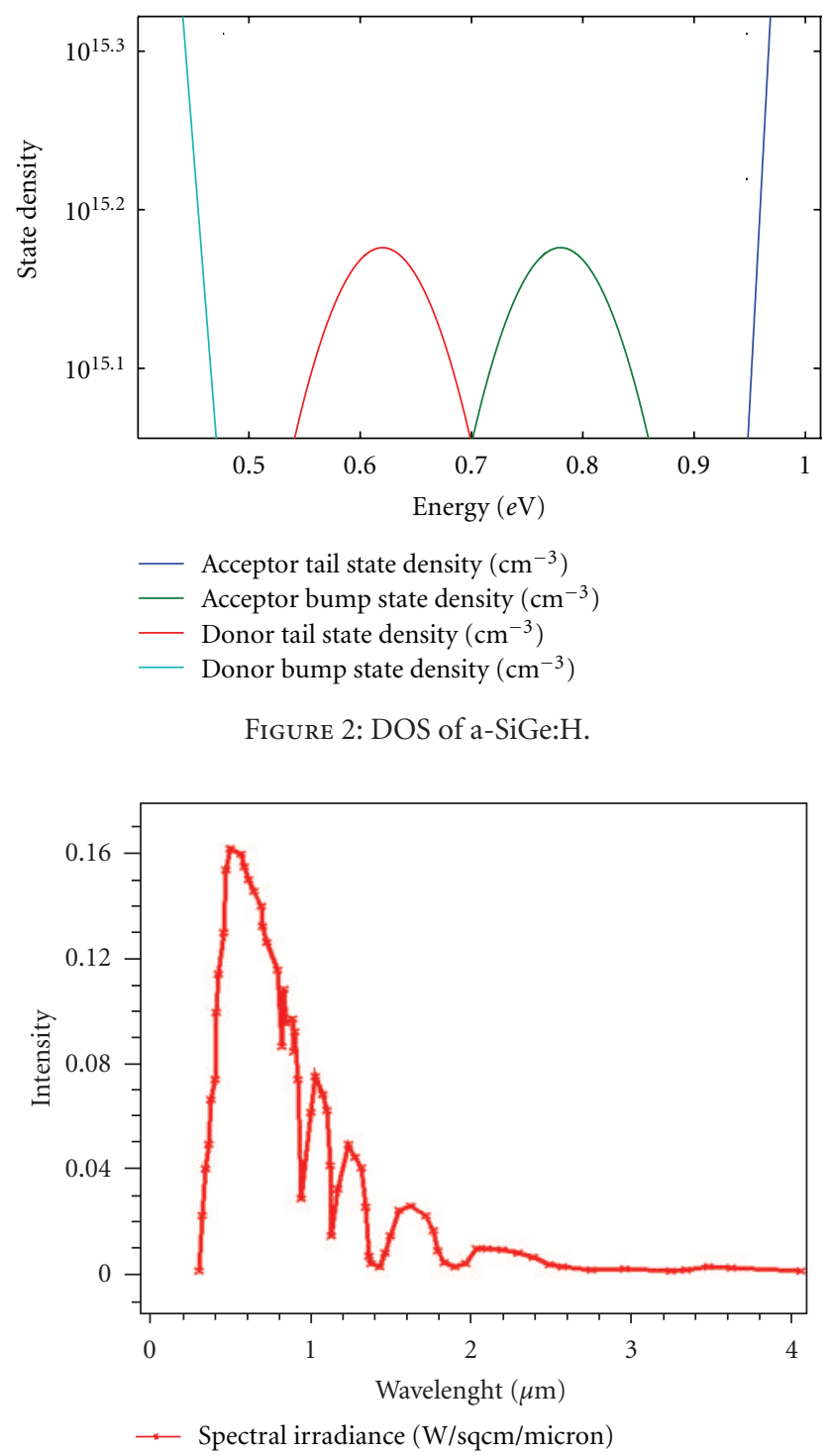

Figure 3: The AM1.5 spectrum.

Disordered materials like amorphous silicon and silicongermanium contain a large amount of defect states within the band gap of the material. To accurately model devices made of amorphous silicon, one should use a continuous density of states. The density of defect states (DOS) is specified with a combination of Gaussian distributions of midgap states and exponentially decaying band tail states $[6,7]$.

2.1. Density of States Model. It is assumed that the total density of state (DOS), $g(E)$, is comprised of four bands: two tail bands (an acceptor-like conduction band and a donor-like valence band) and two deep level bands (one donor-like and the other acceptor-like) which are modelled by a Gaussian distribution:

$$
g(E)=g_{\mathrm{TD}}(E)+g_{\mathrm{TA}}(E)+g_{\mathrm{GD}}(E)+g_{\mathrm{GA}}(E) .
$$

here, $E$ is the trap energy, $E_{\mathrm{C}}$ is the conduction band energy, $E_{\mathrm{V}}$ is the valence band energy and the subscripts $\mathrm{G}, \mathrm{T}, \mathrm{A}$,

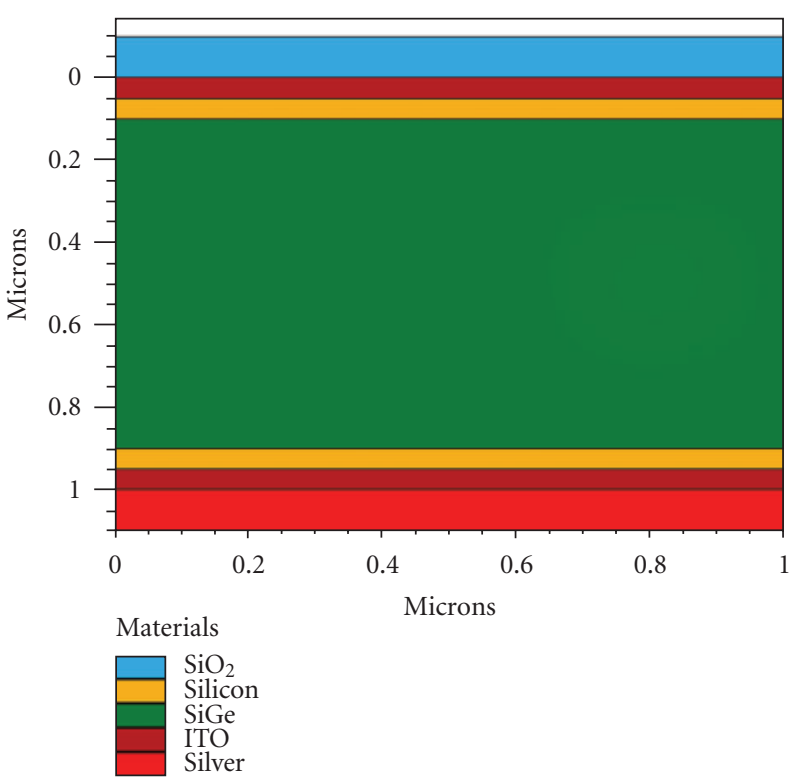

(a)

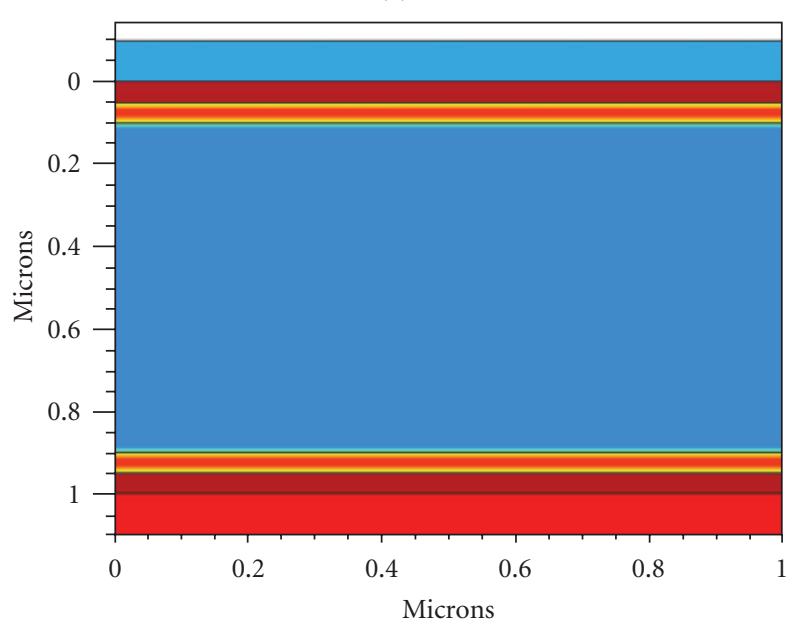

(b)

FIgure 4: The simulated single junction a-SiGe:H solar cell. (a) Layers material. (b) Doping concentration.

and D (Gaussian (deep level)) stand for tail, acceptor and donor states, respectively. Equation (8) describes these four parameters:

$$
\begin{gathered}
g_{\mathrm{TD}}(E)=N_{\mathrm{TD}} \exp \left[\frac{E_{\mathrm{V}}-E}{W_{\mathrm{TD}}}\right], \\
g_{\mathrm{TA}}(E)=N_{\mathrm{TA}} \exp \left[\frac{E-E_{\mathrm{C}}}{W_{\mathrm{TA}}}\right], \\
g_{\mathrm{GA}}(E)=N_{\mathrm{GA}} \exp \left[-\left[\frac{E_{\mathrm{GA}}-E}{W_{\mathrm{GA}}}\right]^{2}\right], \\
g_{\mathrm{GD}}(E)=N_{\mathrm{GD}} \exp \left[-\left[\frac{E-E_{\mathrm{GD}}}{W_{\mathrm{GD}}}\right]^{2}\right] .
\end{gathered}
$$

For an exponential tail distribution, the DOS is described by its conduction and valence band edge intercept densities 


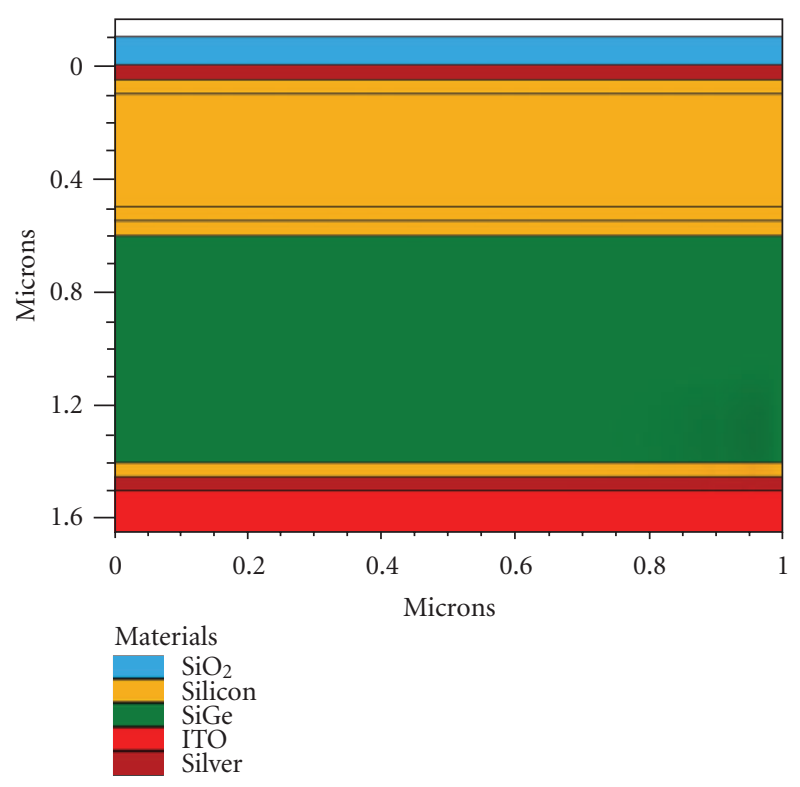

(a)

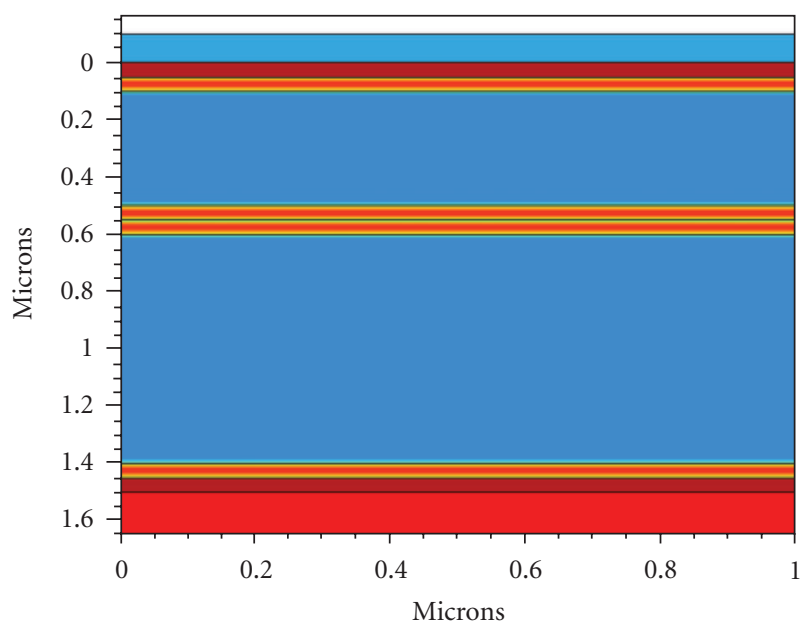

(b)

FIGURE 5: The simulated double junction a-Si:H solar cell. (a) Layers material. (b) Doping concentration.

$\left(N_{\mathrm{TD}}\right.$ and $\left.N_{\mathrm{TA}}\right)$ and by its characteristic decay energy ( $W_{\mathrm{TD}}$ and $\left.W_{\mathrm{TA}}\right)$. For Gaussian distributions, the DOS is described by its peak energy and peak distribution $\left(E_{\mathrm{GD}}\right.$ and $\left.E_{\mathrm{GA}}\right)$, its characteristic decay energy ( $W_{\mathrm{GA}}$ and $\left.W_{\mathrm{GD}}\right)$ and its total density of states $\left(N_{\mathrm{GD}}\right.$ and $\left.N_{\mathrm{GA}}\right)$. Figure 2 shows the DOS and band structure used for a-Si:H and a-SiGe:H material in our model (the $y$ axis has logarithmic scale).

\section{Modelling Process}

The simulation software predicts the electrical characteristics of physical device structures by simulating the transport of carriers through a $2 \mathrm{D}$ grid. The accuracy of this simulation
TABLE 1: The set of input parameters used in the simulation.

\begin{tabular}{|c|c|c|c|}
\hline \multicolumn{4}{|c|}{ a-Si:H/a-SiGe:H/a-Si:H } \\
\hline Layer & p-layer & i-layer & n-layer \\
\hline Thickness (nm) & 50 & 800 & 50 \\
\hline $\begin{array}{l}\text { Doping concentration } \\
\left(/ \mathrm{cm}^{3}\right)\end{array}$ & $6 \times 10^{18}$ & $1 \times 10^{14}$ & $5 \times 10^{18}$ \\
\hline Band gap (eV) & 1.8 & 1.5 & 1.8 \\
\hline $\begin{array}{l}\text { Electron mobility } \\
\left(\mathrm{cm}^{2} / \mathrm{Vs}\right)\end{array}$ & 20 & 20 & 20 \\
\hline Hole mobility $\left(\mathrm{cm}^{2} / \mathrm{Vs}\right)$ & 2 & 2 & 2 \\
\hline $\begin{array}{l}\text { Effective DOS in CB } \\
\left(/ \mathrm{cm}^{3}\right)\end{array}$ & $2.5 \times 10^{20}$ & $1 \times 10^{20}$ & $2.5 \times 10^{20}$ \\
\hline $\begin{array}{l}\text { Effective DOS in VB } \\
\left(/ \mathrm{cm}^{3}\right)\end{array}$ & $2.5 \times 10^{20}$ & $1 \times 10^{20}$ & $2.5 \times 10^{20}$ \\
\hline
\end{tabular}

program depends on the accuracy of the parameters of material used in constructing the device model. Some of the important parameters needed for solar cell modelling are electron and hole state densities, permittivity, radiative recombination rate, band gap energy, electron and hole mobilities, electron affinity, and optical parameters. For simulation of a solar cell, the cell may be illuminated by a complex spectrum such as air mass zero (AM0) or AM1.5 spectrum or a constant wavelength of light. In this simulation the AM1.5 was used. The AM1.5 spectrum is shown in Figure 3.

3.1. Single Junction. The $\mathrm{p}-\mathrm{i}-\mathrm{n}$ structure of the singlejunction a-SiGe:H solar cell $\left(\mathrm{SiO}_{2} / \mathrm{ITO} / \mathrm{p}-\mathrm{a}-\mathrm{Si}: \mathrm{H} / \mathrm{i}-\mathrm{a}-\mathrm{SiGe} \mathrm{H} /\right.$ n-a-Si:H/ITO/silver) with the Gaussian doping concentration is shown in Figure 4. For the p-type layer, a-Si:H with higher doping level has been used because it has higher conductivity, allowing more light pass right through p-layer to reach the intrinsic layer and thereby improving the open circuit voltage as well as the short-circuit current. Also this layer is made thinner than the other layer to give the carriers less opportunity and time to recombine before arriving to the intrinsic layer.

Table 1 shows a set of input parameters, which are used in our simulation. For a-SiGe:H p-i-n solar cell, it is widely accepted that the most important parameter affecting the device properties is the gap states of the films.

3.2. Double Junction. The $\mathrm{p}-\mathrm{i}-\mathrm{n}$ structure of the doublejunction a-Si : H/a-SiGe:H solar cell $\left(\mathrm{SiO}_{2} / \mathrm{ITO} / \mathrm{p}-\mathrm{a}-\mathrm{Si}: \mathrm{H} / \mathrm{i}-\mathrm{a}-\right.$ Si:H/n-a-Si : H/p-a-SiGe:H/i-a-SiGe:H/n-a-SiGe:H/ITO/silver) with the Gaussian doping concentration is shown in Figure 5.

\section{Results and Discussion}

4.1. Single Junction. The parameters of a one-square-meter p-i-n single-junction a-SiGe:H solar cell such as short circuit current $\left(J_{\mathrm{SC}}\right)$, open circuit voltage $\left(V_{\mathrm{OC}}\right)$, fill factor $(\mathrm{FF})$, conversion efficiency, and $I-V$ curve, are obtained as a function of doping concentration, atomic percent of $\mathrm{Ge}$ in a-SiGe layer, and thickness of i-layer and p-layer. 


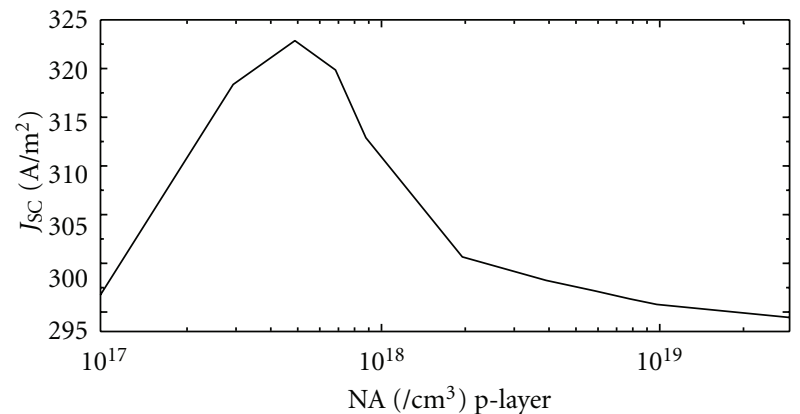

(a)

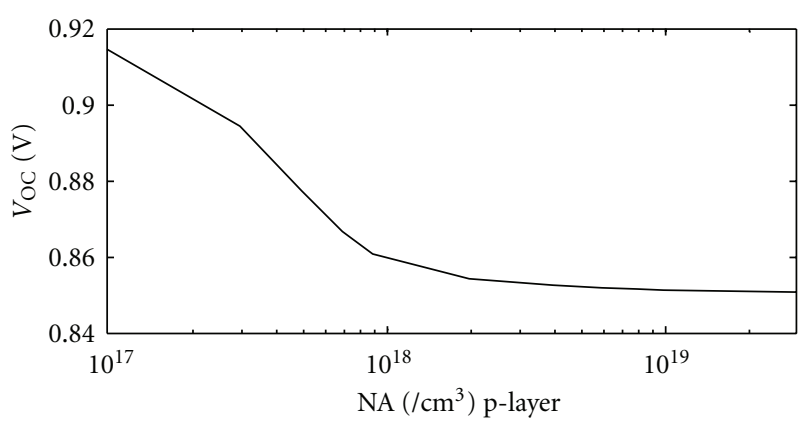

(b)

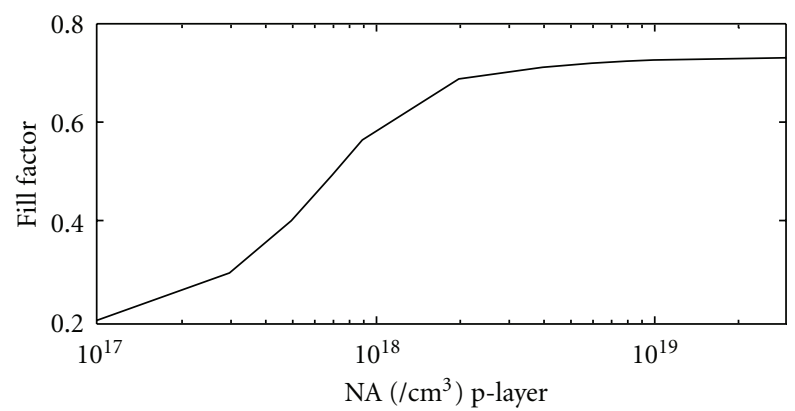

(c)

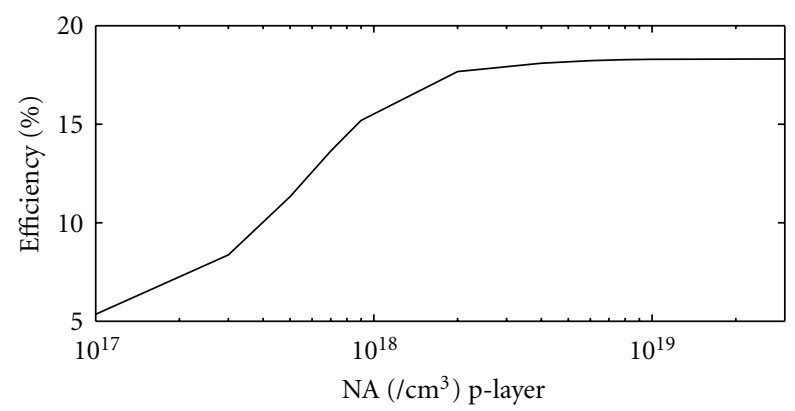

(d)

Figure 6: The dependence of a-SiGe:H solar cell characteristics on the concentration of acceptor in p-layer.

The characteristics of single-junction p-i-n a-SiGe:H solar cell as a function of p-layer doping concentration are shown in Figure 6. The doping concentrations of i-layer, and n-layer are set at $1 \times 10^{14}$ and $5 \times 10^{18} \mathrm{~cm}^{-3}$ for a-SiGe and a-Si layers, respectively. The thickness of p-layer, i-layer and $\mathrm{n}$-layer is also set at $50 \mathrm{~nm}, 800 \mathrm{~nm}$, and $50 \mathrm{~nm}$, respectively.

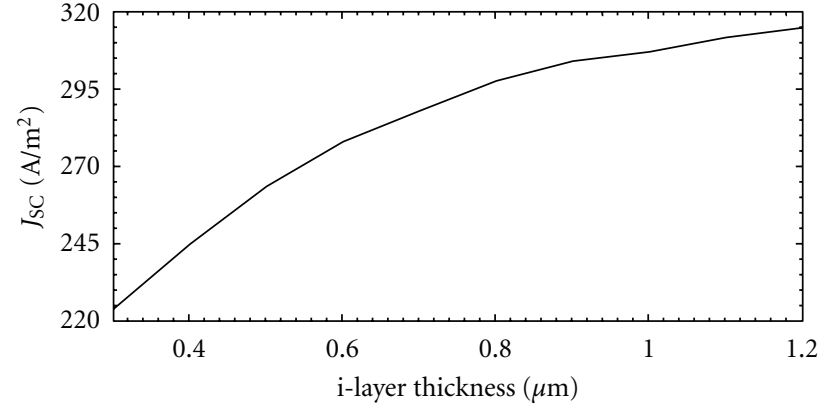

(a)

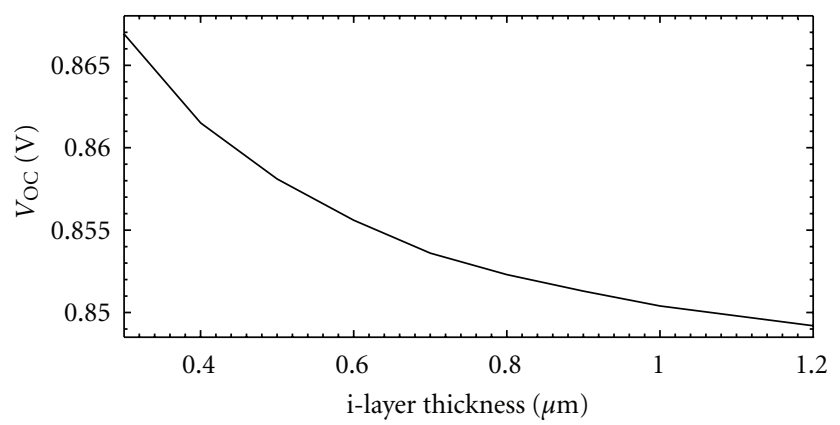

(b)

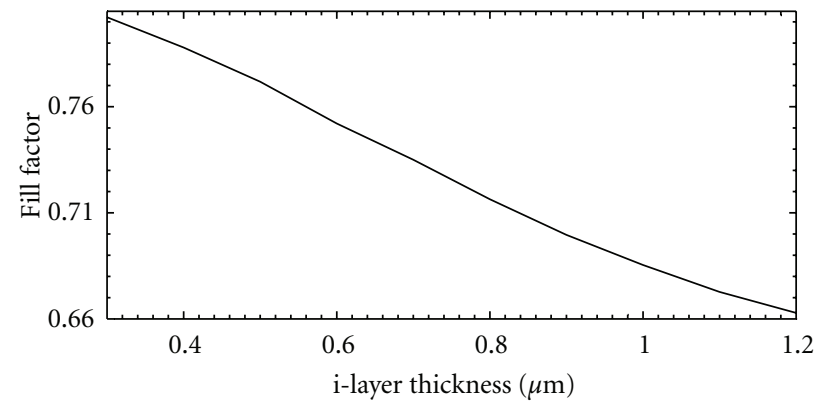

(c)

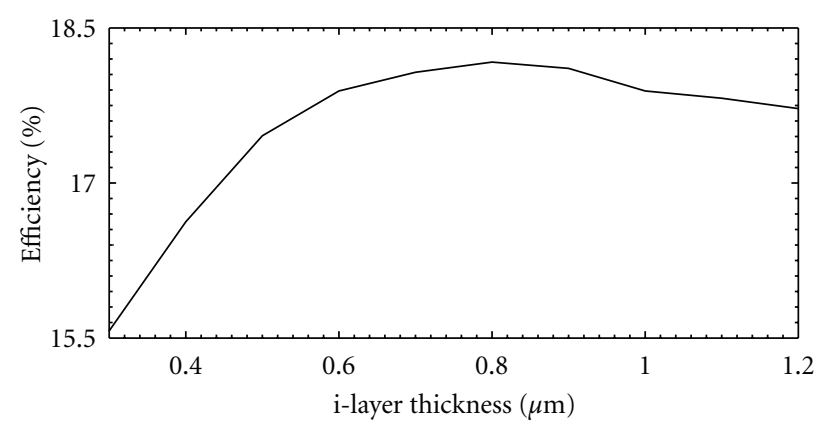

(d)

Figure 7: The solar cell parameters as a function of i-layer thickness in the a- SiGe:H solar cell.

Figure 6 indicates that when the p-layer concentration is more than $5 \times 10^{18} \mathrm{~cm}^{-3}$, the cell has a high efficiency due to the drastic increase in open-circuit voltage of the device. However, in practice it may be difficult to achieve higher acceptor concentration in the film without degrading the film quality. 


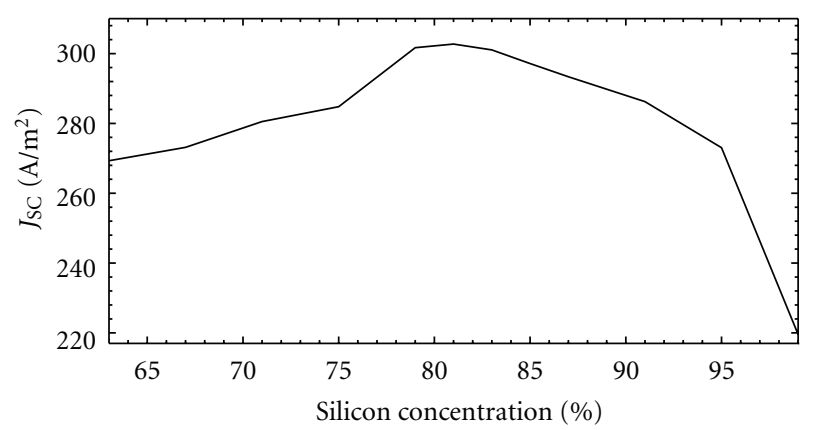

(a)

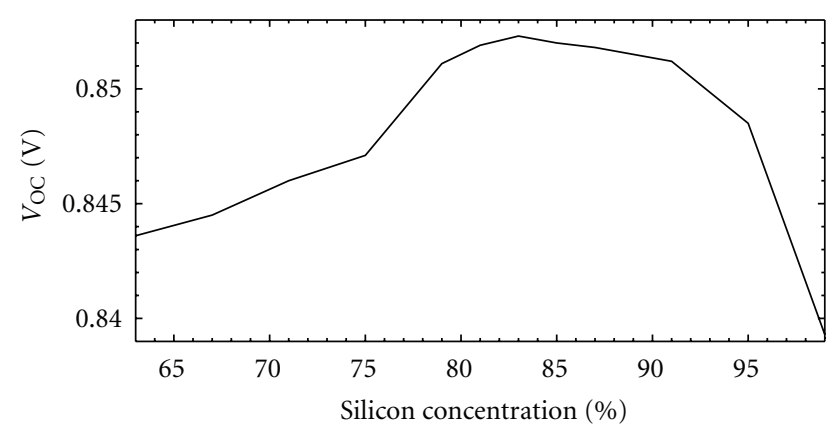

(b)

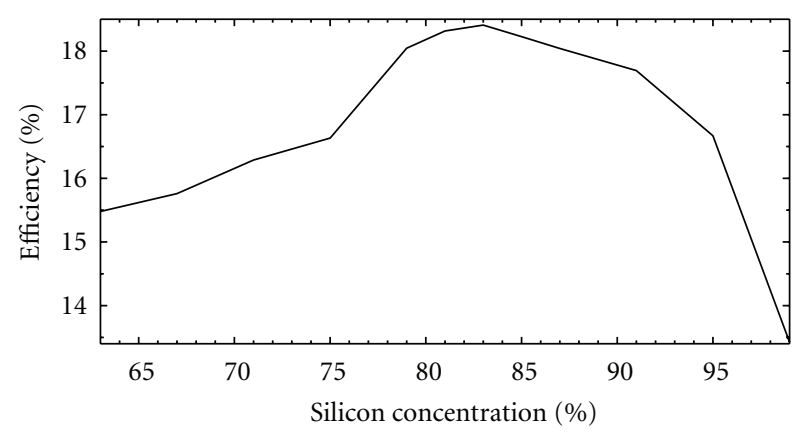

(c)

FIGURE 8: The solar cell parameters as a function of Si concentration in the SiGe layer.

In order to be able to collect the maximum number of electron-hole pairs generated by absorbed photons, the electric field at the p-i interface should be as high as possible; however, the recombination rate also increases with increasing electric field, resulting in a reduction in the efficiency. So, there must be a compromise between the recombination rate and the electric field.

The characteristics of single-junction p-i-n a-SiGe:H solar cell as a function of i-layer thickness are shown in Figure 7. The doping concentration of p-layer, i-layer, and n-layer are set at $5 \times 10^{18}, 1 \times 10^{14}$, and $5 \times 10^{18} \mathrm{~cm}^{-3}$, respectively. The thickness of p-layer and n-layer are also set at $50 \mathrm{~nm}$.

The appropriate addition of Ge in crystalline Si solar cells is an effective method to increase the short-circuit current density, without affecting the open-circuit voltage, due to the modulation of the material band gap and the formation of a heterostructure. The SiGe band gap with different Ge

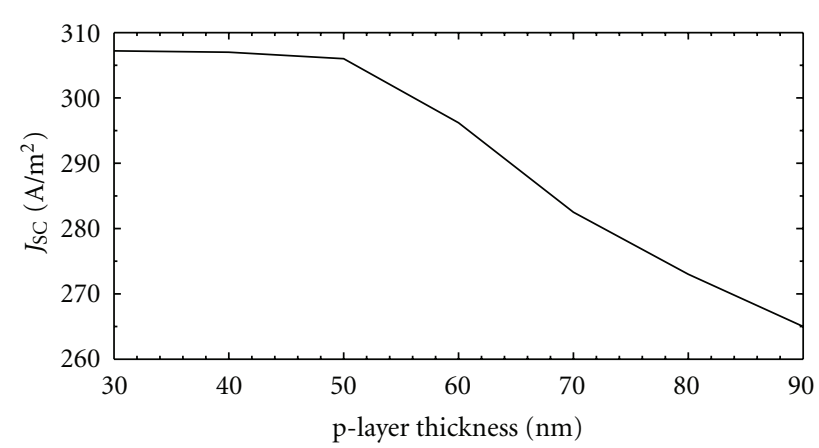

(a)

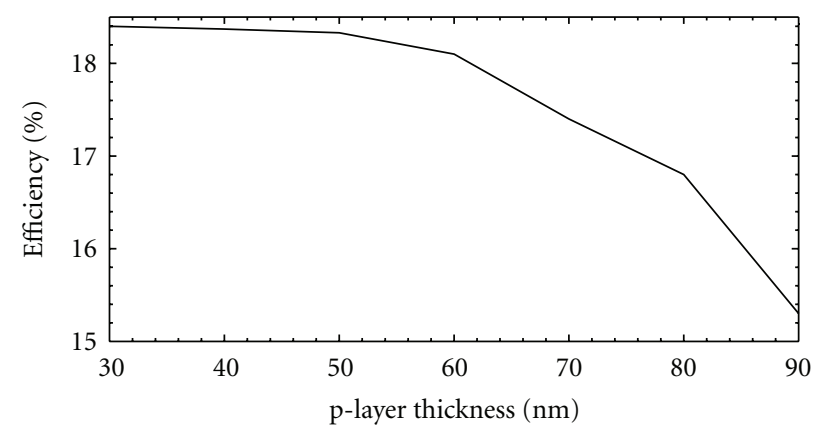

(b)

FIGURE 9: The dependence of a-SiGe:H solar cell characteristics on the thickness of p-layer.

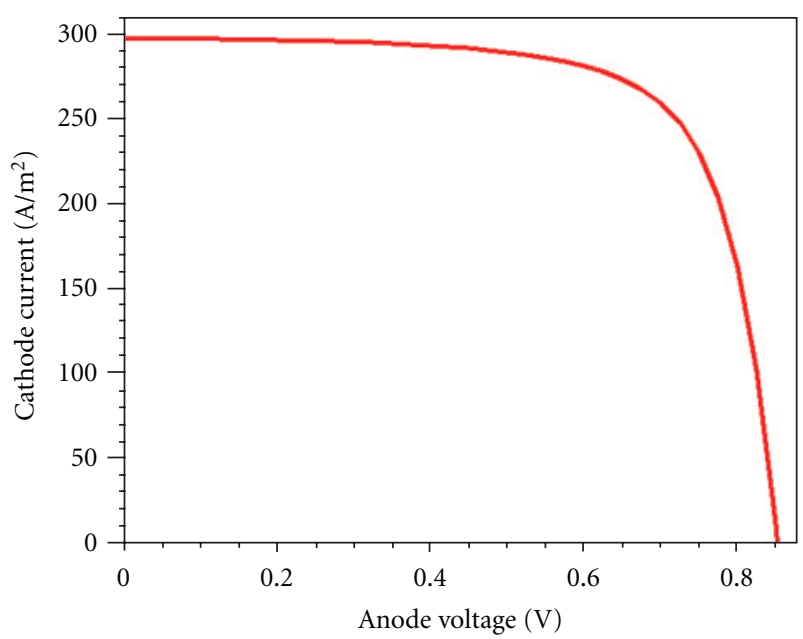

FIgURE 10: $I-V$ characteristics of the single-junction solar cell.

concentrations and temperatures is a key parameter for the $\mathrm{SiGe}$ solar cell design. The characteristics of solar cell as a function of concentration of Ge in SiGe layer between 0-30 at. \% are shown in Figure 8. The thicknesses of p-layer, ilayer, and n-layer is set at 50,800 and $50 \mathrm{~nm}$, respectively, for a-SiGe:H cell. The doping concentrations of p-layer, $\mathrm{i}$ layer, and n-layer are fixed at $6 \times 10^{18}, 1 \times 10^{14}$ and $5 \times$ $10^{18} \mathrm{~cm}^{-3}$ for a-SiGe cell, respectively. As shown in Figure 8, the optimization of $\mathrm{Ge}$ concentration at 17 at. $\%$ of $\mathrm{Ge}$ 


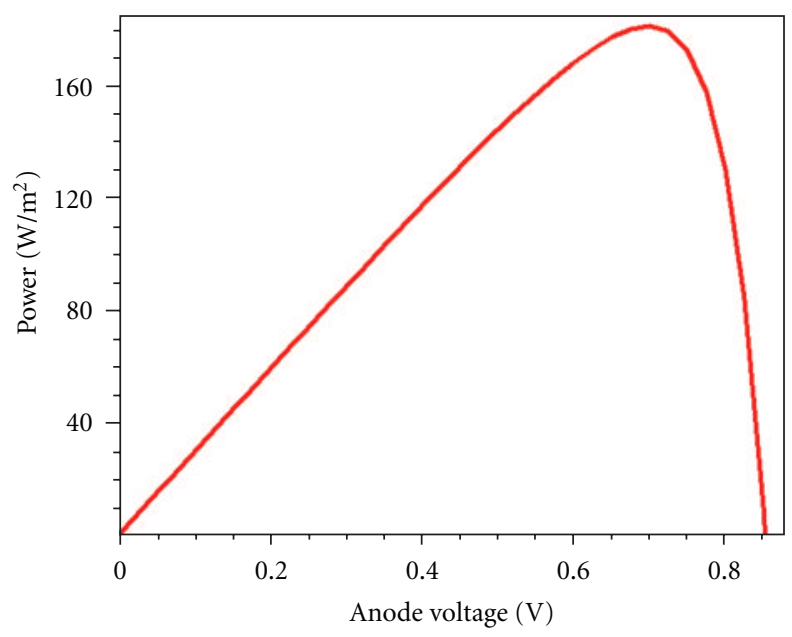

Figure 11: Power efficiency of the single-junction solar cell.

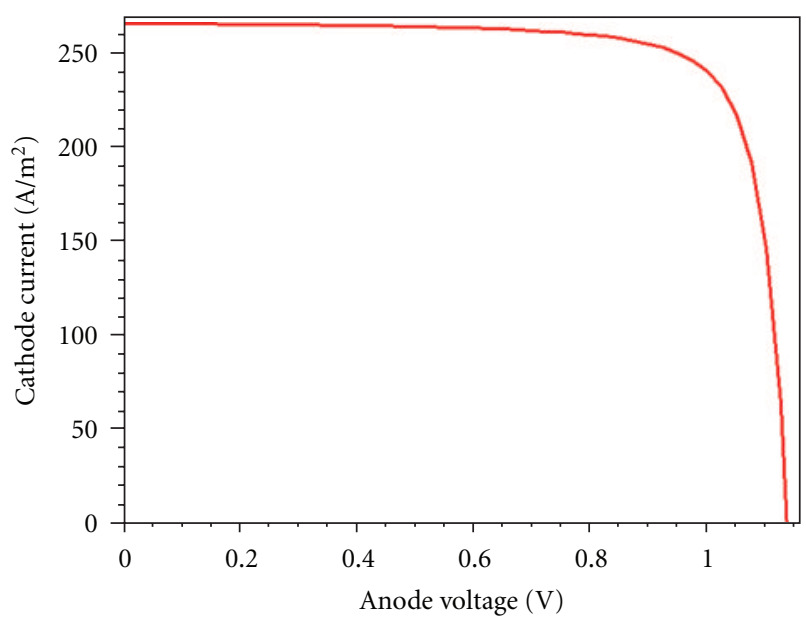

FIGURE 12: $I$ - $V$ characteristics of the double-junction solar cell.

concentration results in about 6\% improvement in the overall efficiency of the $\mathrm{a}-\mathrm{Si}_{0.83} \mathrm{Ge}_{0.17}$ solar cell compared with the traditional single junction a-Si:H solar cell.

The characteristics of single-junction p-i-n a-SiGe:H solar cell as a function of p-layer thickness are shown in Figure 9. The doping concentrations of p-layer, i-layer and n-layer are set at $6 \times 10^{18}, 1 \times 10^{14}$, and $5 \times 10^{18} \mathrm{~cm}^{-3}$, respectively. The thickness of i-layer and n-layer is also set at $800 \mathrm{~nm}$ and $50 \mathrm{~nm}$, respectively.

Figure 9 shows that a cell with thinner p-layer has higher current and finally higher efficiency.

The current-voltage and power-voltage characteristics of optimized single junction solar cell, as a function of electron fluence, for the simulated solar cell are shown in Figures 10 and 11.

4.2. Double Junction. The parameters of a one-square-meter p-i-n double-junction a-Si: $\mathrm{H} / \mathrm{a}-\mathrm{SiGe}$ solar cell such as power and $I$ - $V$ curve based on this optimized single-junction structure are obtained.

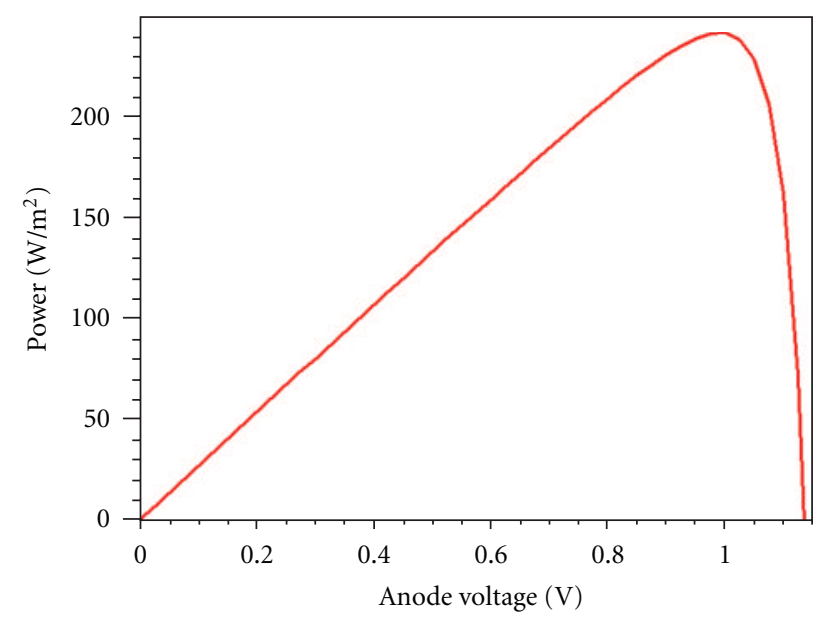

Figure 13: Power efficiency of the double-junction solar cell.

The current-voltage and power-voltage characteristics of double-junction solar cell, as a function of electron fluence, for the simulated solar cell are shown in Figures 12 and 13.

\section{Conclusion}

The results of the two-dimensional computer simulations, which are designed to optimize the double-junction amorphous silicon/amorphous silicon-germanium solar cell, are presented here using the standard continuous density of state model for deep and shallow states in amorphous silicon band gap. The simulation and modelling approach indicates that it is possible to optimize the solar cell performance and improve the efficiency of the cell using optimization of thickness and doping concentration of layers.

Using appropriate combination of $\mathrm{Ge}$ and $\mathrm{Si}$ in the SiGe films of the SiGe-based solar cells, the short-current density has been successfully increased without affecting the opencircuit voltage. As a result the overall efficiency of the cell is also improved.

\section{References}

[1] M. H. Liao and C. H. Chen, "The investigation of optimal Sisige hetero-structure thin-film solar cell with theoretical calculation and quantitative analysis," IEEE Transactions on $\mathrm{Na}$ notechnology, vol. 10, no. 4, pp. 770-773, 2011.

[2] C. Lee, H. Efstathiadis, J. E. Raynolds, and P. Haldar, "Two-dimensional computer modeling of single junction a-Si:H solar cells," in Proceedings of the 34th IEEE Photovoltaic Specialists Conference (PVSC '09), pp. 001118-001122, Philadelphia, Pa, USA, June 2009.

[3] Z. Q. Li, Y. G. Xiao, and Z. M. S. Li, "Modeling of multi-junction solar cells by crosslight APSYS," in High and Low Concentration for Solar Electric Applications, Proceedings of the SPIE, San Diego, Calif, USA.

[4] S. Michael, A. D. Bates, and M. S. Green, "Silvaco atlas as a solar cell modeling tool," in Proceedings of the 31st IEEE Photovoltaic Specialists Conference, pp. 719-721, January 2005.

[5] H. Tasaki, W. Y. Kim, M. Hallerdt, M. Konagai, and K. Takahashi, "Computer simulation model of the effects of interface 
states on high-performance amorphous silicon solar cells," Journal of Applied Physics, vol. 63, no. 2, pp. 550-560, 1988.

[6] M. Kemp, M. Meunier, and C. G. Tannous, "Simulation of the amorphous silicon static induction transistor," Solid State Electronics, vol. 32, no. 2, pp. 149-157, 1989.

[7] B. M. Hack and J. G. Shaw, "Numerical simulations of amorphous and polycrystalline silicon thin-film transistors," in Proceedings of the 22nd International Conference on Solid-State Devices and Materials, pp. 999-1002, Sendai, Japan, 1990. 

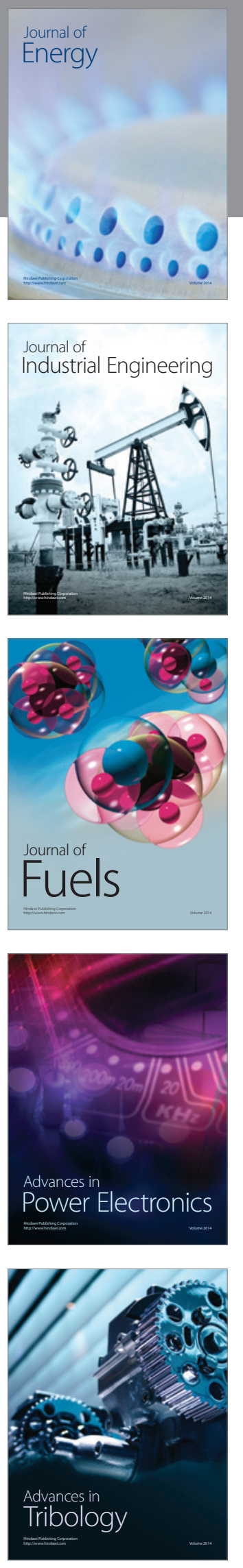
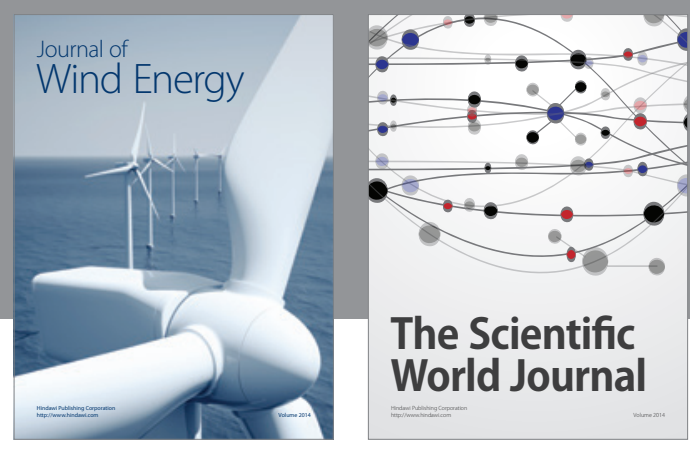

The Scientific World Journal

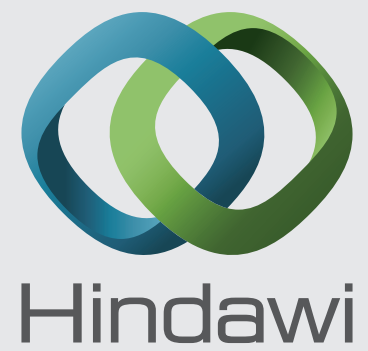

Submit your manuscripts at http://www.hindawi.com
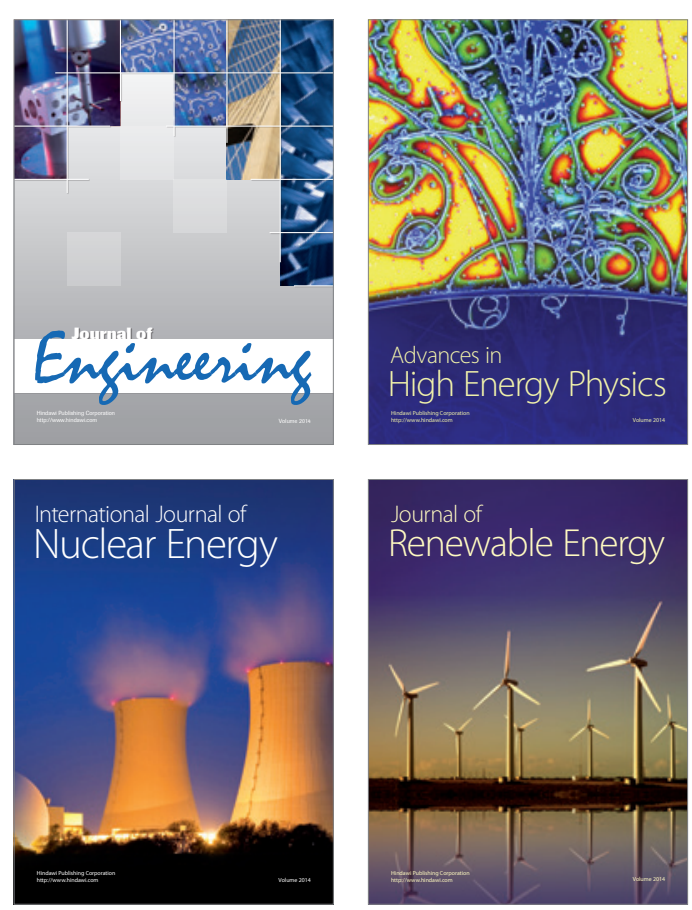

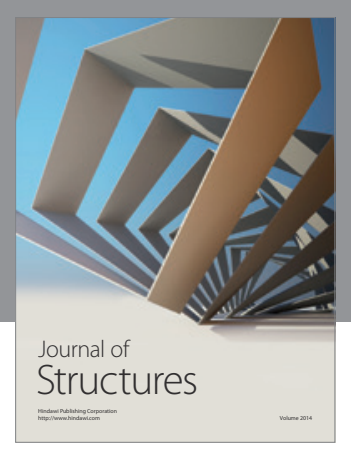

Rotating
Mechinery
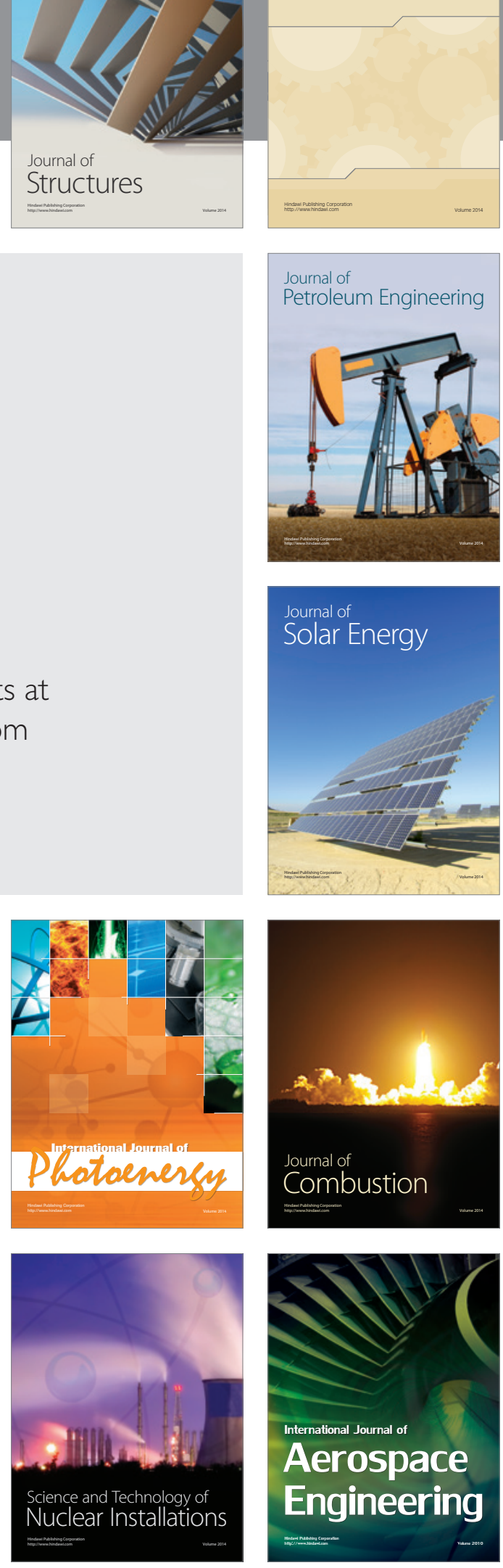